\title{
EFEITOS DE MODOS DE APLICAÇÃO E CONCENTRAÇÕES DE ETEFON NA COLORAÇÃO DA CASCA E OUTROS ATRIBUTOS DE QUALIDADE DO ABACAXI 'PÉROLA'1
}

\author{
LUCIANA LIMA DE ALMEIDA SANTANA², DOMINGO HAROLDO REINHARDT ${ }^{3}$, VALDIQUE MARTINS MEDINA², \\ CARLOS ALBERTO DA SILVA LEDO ${ }^{3}$, RANULFO CORRÊA CALDAS ${ }^{3}$, CLOVIS PEREIRA PEIXOTO²
}

\begin{abstract}
RESUMO - As crescentes exigências do consumidor por uma aparência melhor do abacaxi 'Pérola' têm levado os produtores e intermediários a efetuarem aplicações do fitorregulador etefon sem o devido embasamento técnico-científico, com conseqüências negativas para os frutos e o material de plantio. Este trabalho visou a avaliar os efeitos de modos de aplicação e concentrações de etefon sobre a coloração da casca e outros aspectos externos e internos dos frutos de abacaxi 'Pérola', durante o armazenamento sob condições ambientais. Frutos verdosos foram colhidos e tratados em plantio comercial, em Itaberaba-BA, e, em seguida, armazenados e avaliados na Embrapa Mandioca e Fruticultura, Cruz das Almas-BA. Em delineamento inteiramente casualizado, com esquema fatorial 4 × $3+1$ e número variável de repetições (cinco ou mais), foram estudadas quatro concentrações (500 $\left.\mathrm{mg} \mathrm{L}{ }^{-1}, 1.000 \mathrm{mg} \mathrm{L}^{-1}, 2.000 \mathrm{mg} \mathrm{L}^{-1} \mathrm{e} 4.000 \mathrm{mg} \mathrm{L}^{-1}\right)$ de etefon, ácido 2-cloroetilfosfônico, diluído em água, além do tratamento-testemunha (0 mg L $\left.\mathrm{m}^{-1}\right)$, e três formas de aplicação (pulverização com jato tipo 'filete` dirigido a um lado do fruto na pré-colheita, pulverização sobre os frutos colhidos e acondicionados aleatoriamente em balaios na pós-colheita, e imersão dos frutos, por dez segundos, depois de colhidos, sem atingir as coroas). Aos quatro, cinco, sete e onze dias após a colheita, foram avaliados a coloração e a firmeza da casca, bem como a coloração, firmeza, translucidez, teores de sólidos solúveis totais (SST), acidez (ATT) e a relação SST/ATT da polpa. O etefon acelerou o amarelecimento dos frutos, sem afetar a firmeza da casca e a qualidade interna dos frutos. A imersão determinou amarelecimento mais rápido e uniforme da casca dos frutos do que o observado para as demais formas de aplicação. Os resultados obtidos permitem recomendar a imersão rápida dos frutos de abacaxi 'Pérola', logo após a colheita, em soluções de etefon, nas concentrações de 500 a $2.000 \mathrm{mg} \mathrm{L}^{-1}$.
\end{abstract}

Termos para indexação: Ananas comosus, armazenamento, polpa, firmeza da casca.

\section{EFFECTS OF APPLICATION METHODS AND CONCENTRATIONS OF ETHEPHON ON RIND COLOR AND OTHER QUALITY ATTRIBUTES OF 'PÉROLA' PINEAPPLES}

\begin{abstract}
The increasing demands by consumers for a better fruit appearance have influenced sellers and growers to apply for the growth regulator ethephon on 'Pérola' pineapples without scientifically based knowledge, leading to negative impacts on fruits and planting material (slips). This work aimed at evaluating the effects of application methods and concentrations of ethephon on rind color and other external and internal aspects of 'Pérola' pineapples during their storage under natural conditions. Green-ripe fruits were harvested and treated in a commercial orchard in Itaberaba, Bahia, Brazil, and then transported, stored and evaluated at Embrapa Cassava \& Fruits, Cruz das Almas, Bahia. In a completely randomized experimental design with a $4 \times 3+1$ factorial scheme and five or more replications, were studied four concentrations of ethephon (2-chloroethilphosphonic acid) in water $\left(500 \mathrm{mg} \mathrm{L}^{-1}, 1000 \mathrm{mg} \mathrm{L}^{-1}, 2000 \mathrm{mg} \mathrm{L}^{-1}\right.$ and $\left.4000 \mathrm{mg} \mathrm{L}^{-1}\right)$, besides the control $\left(0 \mathrm{mg} \mathrm{L}^{-1}\right)$, and three forms of application: small jet spraying on one side of the fruit (pre-harvest); broad spraying over the fruits harvested and placed into a basket; and dip immersion of the fruit into solutions during 10 seconds, without touching the crown. Evaluations were done at four, five, seven and eleven days after harvest, on rind color and firmness, as well as on color, translucence, total soluble solids (TSS), total titratable acidity (TTA) and TSS/TTA ratio of the pulp. Ethephon treatment accelerated fruit rind yellowing, without affecting rind firmness and pulp quality. Fast dip treatment of fruits determined a more rapid and even rind yellowing than that observed for the other application forms studied. Results allowed recommending 'Pérola' pineapple fruits to be treated by fast immersion into ethephon solutions at 500 to $2.000 \mathrm{mg} \mathrm{L}^{-1}$.
\end{abstract}

Index terms: Ananas comosus, storage, pulp, rind firmness.

\section{INTRODUÇÃO}

As técnicas de cultivo da cultura do abacaxizeiro têm melhorado bastante nos últimos anos, obtendo-se frutos de boa qualidade, mas esta não é adequadamente mantida na fase pós-colheita (Abreu et al., 1998). O abacaxi brasileiro, representado pelo fruto da cultivar Pérola, mesmo com suas boas características de aroma, paladar e sabor, bem como menores teores de acidez e fibras que os da cv. Smooth Cayenne, tem tido sua aceitação prejudicada devido à coloração inadequada da sua casca (Gonçalves e Carvalho, 2000), considerando que o consumidor nacional está cada vez mais exigente quanto à qualidade do fruto.

Em geral, os frutos são colhidos no estádio "de vez", com casca verde-clara, e chegam aos mercados consumidores com casca ainda predominantemente verde, enquanto o consumidor prefere frutos com a casca mais amarela e vistosa. Para atender a esta exigência, tem sido observado que muitos produtores efetuam aplicações de etefon, na fase pré-colheita (quatro a sete dias antes da colheita) ou imediatamente após a colheita, no momento do seu carregamento no caminhão, quando são pulverizados ainda amontoados nos cestos. Tais práticas, realizadas de forma empírica, sem o respaldo de estudos científicos, têm tido efeitos imprevisíveis e, muitas vezes, conseqüências negativas, a exemplo da perda de filhotes por florações precoces, quando ainda presos às plantasmães ou durante os primeiros meses após o plantio no campo (Reinhardt, 1998) e a desuniformidade na coloração da casca e na qualidade dos frutos oferecidos aos consumidores.

Frutos da 'Smooth Cayenne', variedade cultivada com mudas do tipo rebentão, localizadas na parte inferior da planta (brotação do caule), quando destinados ao comércio internacional, há muitos anos vêm sendo submetidos ao tratamento com etefon pré-colheita para acelerar e uniformizar o amarelecimento da casca. Esta técnica foi desenvolvida a partir de pesquisas realizadas, sobretudo, em países africanos exportadores de abacaxi (Poignant, 1971). Por outro lado, este assunto não tem sido estudado para a cv. Pérola, a não ser por Cunha et al. (1980), que trataram os frutos colhidos por imersão em solução aquosa

\footnotetext{
${ }^{1}$ (Trabalho 137/2003). Recebido: 20/09/2003. Aceito para publicação: 04/08/2004.

${ }^{2}$ Eng $^{\circ}$ Agrônomo, M.Sc., e Professor, D.Sc., respectivamente, da Escola de Agronomia da Universidade Federal da Bahia, Cruz das Almas-BA, fone (0xx75) 621 1220, cppeixot@ufba.br.

${ }^{3}$ Eng $^{0}$ Agr ${ }^{0}$., Pesquisadores (Ph.D., M.Sc., D.Sc., M.Sc. respectivamente) Embrapa Mandioca e Fruticultura, C.P. 7, 44.380-000 Cruz das Almas-BA, Brasil; dharoldo@cnpmf.embrapa.br, medina@cnpmf.embrapa.br, ledo@cnpmf.embrapa.br, rcaldas@cnpmf.embrapa.br, fone (0xx75)6218061.
} 
de etefon $\left(0\right.$ a $\left.2.000 \mathrm{mg} \mathrm{L}^{-1}\right)$ durante três minutos, observando o seu amarelecimento durante $\mathrm{o}$ armazenamento em condições ambientais, mas não avaliaram a influência dos tratamentos na qualidade da polpa dos frutos.

O etileno, que é liberado pelo etefon (ácido 2-cloroetilfosfônico), tem tido efeitos diretos ou indiretos, resultando na degradação da clorofila e, em menor grau, na síntese e/ou aparecimento de carotenóides na casca dos frutos (Abeles et al., 1992). Se utilizado em concentrações e formas de aplicação adequadas, o etefon pode melhorar a coloração amarela da casca do fruto do abacaxi, mas é preciso evitar que os frutos tratados tenham a sua qualidade interna afetada.

Este trabalho visou a avaliar o efeito de modos de aplicação e de concentrações de etefon sobre a coloração e a firmeza da casca e propriedades da polpa de frutos de abacaxi cv. Pérola, durante o seu armazenamento sob condições ambientais.

\section{MATERIAL E MÉTODOS}

O trabalho de campo foi conduzido em área comercial de abacaxi 'Pérola' de sequeiro da Fazenda Lagoa Encantada, Barro Branco, Itaberaba-BA. O município, localizado à altitude de $250 \mathrm{~m}, 10^{\circ} 33^{\prime}$ latitude Sul e $40^{\circ} 25^{\prime}$ longitude Oeste, apresenta clima semi-árido quente, com chuvas de verão e período seco bem definido de inverno, classificado no tipo B.Swh de acordo com Köeppen (SEI, 1998). O plantio estava no seu primeiro ciclo, conduzido de acordo com os tratos culturais usualmente empregados na região (Alves et al., 1998).

O experimento foi instalado quando os frutos apresentaram os frutilhos da sua base passando da cor verde-escura para a verde-clara e da forma pontiaguda para a achatada. Estes frutos verdosos, segundo a classificação oficial (Brasil MAPA, 2002), depois de tratados e colhidos, foram armazenados e avaliados na Embrapa Mandioca e Fruticultura, Cruz das Almas-BA, no período de 23 de dezembro de 2000 a 04 de janeiro de 2001.

O delineamento experimental foi o inteiramente casualizado, em esquema fatorial 4 × $3+1$, com número variável de repetições por tratamento e data de avaliação (período de armazenamento), sendo de, pelo menos, cinco para variáveis como a firmeza da casca, que implicam danificar os frutos (método destrutivo), e 9 a 32 repetições para a variável coloração da casca, usando-se todos os frutos disponíveis em cada data de avaliação (visual). Cada repetição correspondeu a um fruto. $\mathrm{O}$ primeiro fator foi representado pela concentração do fitorregulador etefon (ácido 2-cloroetilfosfônico, produto comercial Ethrel a 24\% i.a.), diluído em água, estudando-se as seguintes concentrações: $500 \mathrm{mg} \mathrm{L}^{-1}, 1.000$ $\mathrm{mg} \mathrm{L}^{-1}, 2.000 \mathrm{mg} \mathrm{L}^{-1} \mathrm{e} 4.000 \mathrm{mg} \mathrm{L}^{-1}$, além da testemunha absoluta $\left(0 \mathrm{mg} \mathrm{L}^{-}\right.$ ${ }^{1}$ ). O segundo fator consistiu em três formas de aplicação do etefon, que foram: 1. Pré-colheita: pulverização feita quatro dias antes da colheita (18-12-2000), com jato tipo 'filete' dirigido a um lado do fruto, sem atingir a coroa nem as mudas do tipo filhote, encontradas ao longo da parte superior do pedúnculo, logo abaixo do fruto (em média, $5 \mathrm{~mL}$ de calda por fruto); 2. Pós-colheita (22-12-2000): pulverização sobre os frutos colhidos e acondicionados aleatoriamente em balaio usualmente empregado para o transporte de frutos dentro do pomar (em média, 50 $\mathrm{mL}$ de calda aplicada por balaio com 25 frutos); 3. Pós-colheita (22-122000): imersão rápida (10 segundos) dos frutos, sem atingir as coroas, realizada no campo, logo após a colheita, antes de serem transportados para o local de armazenamento (em média, $10 \mathrm{~mL}$ de calda por fruto).

Os frutos colhidos e submetidos aos diversos tratamentos pertenciam às categorias $2(1.201 \mathrm{a} 1.500 \mathrm{~g}) \mathrm{e} 1$ (900 a 1.200g), segundo as normas de classificação do abacaxi (Programa, 2003). Eles foram armazenados em condições ambientais $\left(26^{\circ} \mathrm{C} \pm 2^{\circ}\right)$, por períodos de até onze dias, realizando-se avaliações aos quatro, cinco, sete e onze dias após a colheita.

A coloração da casca dos frutos foi avaliada, sempre pelo mesmo avaliador, com base na seguinte escala de notas, adaptada de Giacomelli (1982) e Abdullah et al. (2000): 1 - fruto totalmente verde; 2 - fruto com os primeiros frutilhos da base pintando de amarelo; 3 - fruto com $25 \%$ da área da casca amarela; 4 - fruto com 50\% da área da casca amarela; 5 fruto com $75 \%$ da área da casca amarela; 6 - fruto com $100 \%$ da casca amarela. A firmeza da casca foi determinada na região mediana dos frutos inteiros, nos pontos de coalescência entre frutilhos, sem atingir as áreas das brácteas, com uso de penetrômetro (McCormick FT 327), correspondendo à pressão necessária para fazer uma ponta de prova de seis $\mathrm{mm}$ de diâmetro penetrar $1,5 \mathrm{~cm}$ no fruto. As medições de firmeza da polpa foram feitas na seção horizontal mediana, próximo ao eixo central. Os dados obtidos representam médias de três medições por fruto, analisados estatisticamente $\mathrm{em} \mathrm{kg} \mathrm{cm}{ }^{-2}$ e convertidos para Newton (N) pelo fator 9,807 .

A coloração e a translucidez da polpa foram avaliadas mediante observação de seção transversal mediana do fruto, com base nas seguintes escalas de notas, adaptadas de Giacomelli (1982) e Abdullah et al. (2000): 1 - polpa branca; 2 - polpa branca com algum amarelo; 3 polpa mais branca que amarela; 4 - polpa mais amarela que branca; 5 polpa amarela; 6 - polpa amarelo-ouro (coloração); 1 - Polpa completamente opaca; 2 - polpa com até $25 \%$ de área translúcida; 3 polpa com $26 \%$ a $50 \%$ de área translúcida; 4 - polpa com $51 \%$ a $75 \%$ de área translúcida; 5 - polpa com mais de $75 \%$ de área translúcida. Os teores de sólidos solúveis totais (SST) e da acidez total titulável (ATT) foram determinados, respectivamente, com uso de refratômetro e por titulação com $\mathrm{NaOH}$ a $0,1 \mathrm{M}$, em amostra de suco extraída de seção diagonal longitudinal do fruto, representando um quarto de cada uma de suas metades superior e inferior. Calculou-se também a relação SST/ ATT. Além disso, foram feitas observações visuais sobre a ocorrência de eventuais problemas que prejudiquem a aparência dos frutos, sobretudo a desidratação das folhas das coroas.

Os dados obtidos foram submetidos à análise de variância e as médias comparadas pelo teste de Tukey, a 5\% de probabilidade.

\section{RESULTADOS E DISCUSSÃO}

Coloração da casca - O modo de aplicação e a concentração do etefon e a interação destes dois fatores tiveram efeitos significativos sobre a coloração da casca aos quatro, cinco e sete dias após a colheita. Na última avaliação, realizada aos 11 dias, apenas o modo de aplicação do etefon ainda influenciou significativamente nesta variável, o mesmo ocorrendo com a interação dos dois fatores (análise de variância não mostrada).

Quanto aos modos de aplicação estudados, a imersão promoveu amarelecimento mais rápido dos frutos, sendo superior às demais formas de aplicação do etefon, em todas as datas de avaliação, salvo em relação à pulverização pré-colheita aos cinco dias de armazenamento (Tabela 1). Nas diversas concentrações de etefon e datas de avaliação estudadas, os valores obtidos para a coloração da casca foram, na maioria das vezes, os mais altos para os frutos tratados por imersão rápida. Estes atingiram, na média, quase 50\% (nota 3,95) da área da casca com coloração amarela, aos quatro dias após a colheita, e mais de 50\% da mesma (nota $4,25)$ um dia mais tarde. Quando imersos nas caldas com as concentrações mais altas de etefon $\left(2.000\right.$ e $\left.4.000 \mathrm{mg} \mathrm{L}^{-1}\right)$, a coloração amarela da casca foi ainda mais intensa, chegando a cobrir de 60 a 75\% da área da casca (notas 4,4 a 5,0), aos cinco dias após a colheita.

A literatura é escassa no que diz respeito a estudos que comparem formas de aplicação de etefon com vistas ao controle do amadurecimento do abacaxi. A prática comum tem sido a pulverização deste fitorregulador sobre os frutos antes da sua colheita, sobretudo em frutos da cultivar Smooth Cayenne destinados à exportação (Rebolledo et al., 1998). No entanto, nesta forma de aplicação, o etefon pode atingir as mudas do tipo filhote, geralmente presentes em plantas da cv. Pérola, induzindo-as à floração precoce e inutilizando-as como material de plantio. Um dos poucos trabalhos com a cv. Pérola foi o de Cunha et al. (1980), que estudaram apenas o tratamento dos frutos por imersão, por três minutos, sendo armazenados em condições ambientais (cerca de $28^{\circ} \mathrm{C}$ ). Os frutos começaram a amarelecer, de maneira uniforme, um dia após o tratamento, com a coloração evoluindo por até nove dias, quando 
TABELA 1 - Efeito do modo de aplicação do etefon, em função da concentração $\left(\mathrm{mg} \mathrm{L}^{-1}\right)$, sobre a coloração da casca (notas da escala de 1 a 6 , em ordem crescente de coloração amarela) do fruto de abacaxi cv. Pérola, em quatro períodos de armazenamento pós-colheita. Cruz das Almas-BA, 2001.

\begin{tabular}{|c|c|c|c|c|c|}
\hline \multirow{2}{*}{ Modo de Aplicação } & \multicolumn{4}{|c|}{ Concentração $\left(\mathrm{mg} \mathrm{L}^{-1}\right)^{z}$} & \multirow{2}{*}{ Média } \\
\hline & 500 & 1.000 & 2.000 & 4.000 & \\
\hline & \multicolumn{4}{|c|}{ Quatro dias após a colheita } & \\
\hline Pulverização pré-colheita & $3,07 \mathrm{~b}$ & $3,76 \mathrm{a}$ & $3,72 \mathrm{~b}$ & $3,85 \mathrm{~b}$ & $3,61 \mathrm{~b}$ \\
\hline Pulverização pós-colheita & $2,95 \mathrm{~b}$ & $3,10 \mathrm{~b}$ & $4,25 \mathrm{a}$ & $3,60 \mathrm{~b}$ & $3,48 \mathrm{~b}$ \\
\hline Imersão & $3,75 \mathrm{a}$ & $3,60 \mathrm{a}$ & $4,00 \mathrm{a} \mathrm{b}$ & $4,45 \mathrm{a}$ & $3,95 \mathrm{a}$ \\
\hline Média & 3,24 & 3,55 & 3,97 & 3,95 & 3,67 \\
\hline \multirow[t]{2}{*}{ Testemunha $\left(0 \mathrm{mg} \mathrm{L}^{-1}\right)$} & & & & & $2,56 * *$ \\
\hline & \multicolumn{4}{|c|}{ Cinco dias após a colheita } & \\
\hline Pulverização pré-colheita & $3,40 \mathrm{a} \mathrm{b}$ & $4,00 \mathrm{a}$ & $4,20 \mathrm{a}$ & $4,40 \mathrm{a}$ & $4,00 \mathrm{a}$ \\
\hline Pulverização pós-colheita & $3,00 \mathrm{~b}$ & $3,20 \mathrm{~b}$ & $4,60 \mathrm{a}$ & $3,60 \mathrm{~b}$ & $3,60 \mathrm{~b}$ \\
\hline Imersão & $3,80 \mathrm{a}$ & $3,80 \mathrm{ab}$ & $4,40 \mathrm{a}$ & $5,00 \mathrm{a}$ & $4,25 \mathrm{a}$ \\
\hline Média & 3,40 & 3,67 & 4,40 & 4,33 & 3,95 \\
\hline \multirow[t]{2}{*}{ Testemunha $\left(0 \mathrm{mg} \mathrm{L}^{-1}\right)$} & & & & & $3,20 * *$ \\
\hline & \multicolumn{4}{|c|}{ Sete dias após a colheita } & \\
\hline Pulverização pré-colheita & $4,00 \mathrm{~b}$ & $4,74 \mathrm{a}$ & $4,50 \mathrm{~b}$ & $4,61 \mathrm{~b}$ & $4,47 \mathrm{~b}$ \\
\hline Pulverização pós-colheita & $4,07 \mathrm{~b}$ & $3,71 \mathrm{a}$ & $5,20 \mathrm{a}$ & $4,60 \mathrm{~b}$ & $4,40 \mathrm{~b}$ \\
\hline Imersão & $5,27 \mathrm{a}$ & $4,93 \mathrm{a}$ & $5,47 \mathrm{a}$ & $6,00 \mathrm{a}$ & $5,36 \mathrm{a}$ \\
\hline Média & 4,40 & 4,52 & 5,00 & 4,89 & 4,70 \\
\hline \multirow[t]{2}{*}{ Testemunha $\left(0 \mathrm{mg} \mathrm{L}^{-1}\right)$} & & & & & $3,57 * *$ \\
\hline & \multicolumn{4}{|c|}{ Onze dias após a colheita } & \\
\hline Pulverização pré-colheita & $5,50 \mathrm{a}$ & $5,83 \mathrm{ab}$ & $5,33 \mathrm{~b}$ & $5,58 \mathrm{a}$ & $5,57 \mathrm{~b}$ \\
\hline Pulverização pós-colheita & $5,50 \mathrm{a}$ & $5,33 \mathrm{~b}$ & $5,90 \mathrm{a}$ & $5,90 \mathrm{a}$ & $5,66 \mathrm{~b}$ \\
\hline Imersão & $6,00 \mathrm{a}$ & $6,00 \mathrm{a}$ & $6,00 \mathrm{a}$ & $6,00 \mathrm{a}$ & $6,00 \mathrm{a}$ \\
\hline Média & 5,60 & 5,73 & 5,65 & 5,75 & 5,68 \\
\hline Testemunha $\left(0 \mathrm{mg} \mathrm{L}^{-1}\right)$ & & & & & $5,50^{\mathrm{ns}}$ \\
\hline
\end{tabular}

${ }^{\mathrm{z}}$ Médias seguidas pela mesma letra na coluna não diferem estatisticamente entre si, pelo teste de Tukey, a 5\% de probabilidade.

** Significativo a $1 \%$ de probabilidade pelo teste de $\mathrm{F}$ em relação à média dos tratamentos. ns = não significativo

C.V. $(\%)=15,7$ (4 dias), 12,3 (5 dias), 14,1 (7 dias), 8,9 (11 dias).

atingiram o estado de "passado". No presente estudo, os frutos tiveram vida de prateleira mais longa, permitindo a realização de avaliações até onze dias após a colheita, talvez devido às temperaturas um pouco mais baixas $\left(26 \pm 2^{\circ} \mathrm{C}\right)$ reinantes no local de armazenamento.

Todas as concentrações de etefon estudadas determinaram um maior amarelecimento da casca dos frutos em relação ao controle, nas avaliações aos quatro, cinco e sete dias após a colheita (Tabela 1). Já aos 11 dias após a colheita, tais diferenças desapareceram, pois os frutoscontrole também exibiram cascas quase totalmente amarelas. Ficou evidente que a aplicação do etefon acelerou o amarelecimento dos frutos do abacaxi cv. Pérola durante o período pós-colheita sob condições ambientais, fenômeno que também ocorreu nos frutos-testemunha, mas de uma forma muito mais lenta. Isto confirmou os resultados de vários estudos sobre o abacaxi da cultivar Smooth Cayenne, na qual tem predominado o uso de concentrações de etefon na faixa de $400 \mathrm{mg} \mathrm{L}^{-1}$ a $2.000 \mathrm{mg} \mathrm{L}^{-1}$, aplicados em pré-colheita, portanto concentrações muito próximas às utilizadas neste trabalho (Poignant, 1971; Rebolledo et al., 1998). Cunha et al. (1980) estudaram concentrações de etefon de até $2.000 \mathrm{mg} \mathrm{L}^{-1}$, mas não determinaram a melhor concentração para a imersão pós-colheita dos frutos da cv. Pérola.

$\mathrm{Na}$ definição da concentração do etefon mais indicada para o amarelecimento do abacaxi, precisa ser levada em conta a preferência do consumidor. Este quer fruto doce, normalmente associando casca amarela com paladar mais doce (Brasil.MI, 2002). No entanto, o consumidor geralmente não exige fruto totalmente amarelo, pois isto sugere estádio de maturação mais avançado e, portanto, provavelmente menor tempo de vida útil para o consumo. Se o objetivo do vendedor for ofertar frutos com cerca de $50 \%$ da casca amarela (nota 4,0), o tratamento dos frutos com etefon, na lavoura, deve visar a atingir esta meta dentro do prazo exigido para transportá-los até os mercados, o que normalmente representa um intervalo de três a quatro dias para os mercados nacionais distantes das áreas produtoras de abacaxi. Nesse caso, os tratamentos com etefon, nas concentrações mais altas $\left(2.000 \mathrm{mg} \mathrm{L}^{-1} \mathrm{e} 4.000 \mathrm{mg} \mathrm{L}^{-1}\right)$, atingiram este objetivo (Tabela 1). No entanto, nestas concentrações, foi observada a ocorrência de maior número de folhas secas (queima) na parte inferior da coroa, o que pode prejudicar a sua aparência geral, uma vez que coroas verdes e com folhas intumescidas são indicativos de frutos mais frescos. Assim, devem ser usadas concentrações de etefon as mais baixas possíveis, tais como as de 500 e $1.000 \mathrm{mg} \mathrm{L}^{-1}$, que determinaram colorações da casca iguais ou superiores a $40 \%$ (notas $\geq$ 3,6 ), aos quatro dias após a colheita, nos tratamentos por imersão dos frutos.

No tratamento por pulverização pós-colheita e, em menor grau, no de pré-colheita, o amarelecimento da casca foi muito menos uniforme que o observado nos frutos tratados por imersão, no qual houve uma cobertura mais uniforme da casca com a calda do etefon.

Firmeza da casca e atributos da polpa - As análises de variância não evidenciaram efeitos significativos para o fator "concentração de etefon" e a sua interação com o fator "forma de aplicação do etefon", sobre as variáveis de firmeza da casca e de qualidade da polpa estudadas, dentro de cada período de armazenamento dos frutos (dados não mostrados). Desta forma, é apresentada apenas uma comparação resumida entre os resultados médios gerais obtidos para os tratamentos com etefon e os da testemunha, ao longo do período de armazenamento (Tabela 2). Notam-se valores similares para etefon e testemunha para todas as variáveis avaliadas, dentro de cada período de armazenamento dos frutos, ficando evidente que as concentrações do etefon estudadas, de $500 \mathrm{mg} \mathrm{L}^{-1}$ a $4.000 \mathrm{mg} \mathrm{L}^{-1}$, não afetaram significativamente a qualidade interna dos frutos e a firmeza da casca.

Ao longo do período de armazenamento, houve algumas alterações bastante claras nos valores obtidos para alguns dos atributos de qualidade dos frutos de abacaxi, com poucas diferenças entre os tratamentos com etefon e a testemunha sem etefon . A firmeza da casca do fruto diminuiu entre cinco e onze dias após a colheita para frutos tratados (redução de $46 \%$ ) e não tratados com etefon (redução de 35\%). Este resultado confirmou o relato de Botrel e Abreu (1994), segundo o 
TABELA 2 - Comparação de valores médios relativos à firmeza da casca e propriedades da polpa de frutos de abacaxi 'Pérola', tratados com etefon, com os de frutos sem tratamento (controle), ao longo do período de armazenamento sob condições ambientais. Cada valor expressa média de 20 valores (etefon) e 5 valores (testemunha). Cruz das Almas-BA, 2001.

\begin{tabular}{|c|c|c|c|c|c|c|}
\hline \multirow{3}{*}{ Atributos } & \multicolumn{6}{|c|}{ Tempo de armazenamento pós -colheita } \\
\hline & \multicolumn{2}{|c|}{ Cinco Dias } & \multicolumn{2}{|c|}{ Sete Dias } & \multicolumn{2}{|c|}{ Onze Dias } \\
\hline & Etefon & Controle & Etefon & Controle & Etefon & Controle \\
\hline Firmeza da casca (Newton) & 57,27 & 50,21 & 36,58 & 36,28 & 30,89 & 32,66 \\
\hline Polpa: & & & & & & \\
\hline Firmeza (Newton) & 8,24 & 8,04 & 7,26 & 7,06 & 5,20 & 5,49 \\
\hline Coloração (notas de 1 a 6) & 2,50 & 2,60 & 2,75 & 2,40 & 2,94 & 2,00 \\
\hline Translucidez (notas de 1 a 5 ) & 2,41 & 2,60 & 2,73 & 2,40 & 3,16 & 2,66 \\
\hline SST $\left({ }^{\circ}\right.$ Brix $)$ & 12,90 & 12,54 & 12,22 & 12,72 & 12,94 & 12,60 \\
\hline ATT (\% ácido cítrico) & 0,49 & 0,52 & 0,54 & 0,56 & 0,59 & 0,61 \\
\hline SST/ATT & 26,3 & 24,1 & 22,6 & 22,7 & 21,9 & 20,7 \\
\hline
\end{tabular}

Não houve diferenças significativas pelo teste $\mathrm{F}$, entre tratamentos com etefon e o controle, para as variáveis mencionadas, dentro de cada tempo de armazenamento pós-colheita.

qual, tal redução ocorre principalmente em temperaturas acima de $20^{\circ} \mathrm{C}$, como foi o caso deste trabalho. A mesma tendência de queda, mas em proporção inferior (31\% a $37 \%$ ) ao da casca, ocorreu para a firmeza da polpa.

Os valores da coloração e da translucidez da polpa variaram relativamente pouco ao longo do período de armazenamento, mas houve uma tendência de sua elevação para frutos tratados com etefon (Tabela 2). Resultados similares foram observados por Poignant (1971). Os teores de sólidos solúveis totais oscilaram entre valores de $12 \%$ e $13 \%$, sem efeitos significativos do etefon. A acidez da polpa aumentou (18\% a $20 \%$ ) com o avanço do período de armazenamento, para frutos tratados e frutos-testemunha, resultando numa redução progressiva (17\% a 18\%) da relação SST/ATT. Isto afeta diretamente a qualidade do fruto e sugere que o abacaxi, embora classificado como não-climatérico, pode apresentar alterações relevantes nas suas propriedades químicas e físico-químicas na fase pós-colheita.
O modo de aplicação do etefon determinou efeitos significativos sobre alguns atributos do fruto. Os tratamentos por pulverização pré-colheita conferiram, em média, menor firmeza à casca dos frutos aos cinco e onze dias de armazenamento, quando comparados aos tratamentos por imersão (Tabela 3). A imersão dos frutos também determinou menor acidez e maiores valores para sólidos solúveis totais e SST/ATT aos cinco dias após a colheita, em relação à pulverização pré-colheita, o que pode ser atribuído ao período de quatro dias mais longo de ação do fitorregulador sobre os frutos nos tratamentos com aplicação pré-colheita. O tratamento dos frutos por imersão resultou numa maior translucidez da polpa aos onze dias após a colheita, em relação à pulverização pós-colheita dos frutos (Tabela 3). Por outro lado, a firmeza da polpa e a sua coloração não foram significativamente influenciadas pela forma de aplicação do etefon (dados não mostrados).

Em geral, os resultados evidenciaram que os efeitos do etefon sobre a firmeza da casca e os aspectos internos do abacaxi são muito

TABELA 3 - Efeito do modo de aplicação de etefon sobre a (A) firmeza da casca (Newton) e as seguintes propriedades da polpa de frutos de abacaxi 'Pérola', armazenados sob condições ambientais por períodos diferentes: B) Translucidez (notas de 1 a 5, em ordem crescente); C) Teor de sólidos solúveis totais - SST ( ${ }^{\circ}$ Brix); D) Teor de acidez total titulável - ATT (\% ácido cítrico); E) Relação SST/ATT. Cada valor expressa médias de 20 medições (cinco repetições x quatro concentrações de etefon). Cruz das Almas-BA, 2001.

\begin{tabular}{|c|c|c|c|}
\hline \multirow[t]{2}{*}{ Modo de Aplicação } & \multicolumn{3}{|c|}{ Tempo de armazenamento pós-colheita } \\
\hline & Cinco Dias & Sete Dias & Onze Dias \\
\hline (A) Pulverização pré-colheita & $52,17 \mathrm{~b}$ & $35,30 \mathrm{a}$ & $28,24 \mathrm{~b}$ \\
\hline Pulverização pós-colheita & $57,27 \mathrm{a} \mathrm{b}$ & $37,27 \mathrm{a}$ & $32,55 \mathrm{a}$ \\
\hline Imersão & $62,47 \mathrm{a}$ & $37,17 \mathrm{a}$ & $31,77 \mathrm{a}$ \\
\hline Média & 57,27 & 36,58 & 30,89 \\
\hline C.V. $(\%)$ & 18,8 & 12,5 & 9,7 \\
\hline (B) Pulverização pré-colheita & $2,35 \mathrm{a}$ & $2,70 \mathrm{a}$ & $3,25 \mathrm{ab}$ \\
\hline Pulverização pós-colheita & $2,55 \mathrm{a}$ & $2,75 \mathrm{a}$ & $2,83 b$ \\
\hline Imersão & $2,35 \mathrm{a}$ & $2,75 \mathrm{a}$ & $3,41 \mathrm{a}$ \\
\hline Média & 2,41 & $2,73 a$ & 3,16 \\
\hline C.V. $(\%)$ & 25,2 & 25,7 & 16,2 \\
\hline (C) Pulverização pré-colheita & $12,54 \mathrm{~b}$ & $12,34 a$ & $12,98 \mathrm{a}$ \\
\hline Pulverização pós-colheita & $12,88 \mathrm{ab}$ & $12,31 \mathrm{a}$ & $13,12 \mathrm{a}$ \\
\hline Imersão & $13,29 \mathrm{a}$ & $12,01 \mathrm{a}$ & $12,73 \mathrm{a}$ \\
\hline Média & 12,90 & 12,22 & 12,94 \\
\hline C.V $(\%)$ & 6,2 & 7,6 & 6,9 \\
\hline (D) Pulverização pré-colheita & $9,30 \mathrm{a}$ & $10,20 \mathrm{a}$ & $10,41 \mathrm{a}$ \\
\hline Pulverização pós-colheita & 8,49 a b & $9,52 \mathrm{a} \mathrm{b}$ & $10,17 \mathrm{a}$ \\
\hline Imersão & $8,23 \mathrm{~b}$ & $8,92 \mathrm{~b}$ & $10,75 \mathrm{a}$ \\
\hline Média & 8,67 & 9,54 & 10,45 \\
\hline C.V. $(\%)$ & 13,5 & 16,9 & 6,2 \\
\hline (E) Pulverização pré-colheita & $1,37 \mathrm{~b}$ & $1,25 \mathrm{a}$ & $1,25 \mathrm{a}$ \\
\hline Pulverização pós-colheita & $1,55 \mathrm{a} \mathrm{b}$ & $1,31 \mathrm{a}$ & $1,29 \mathrm{a}$ \\
\hline Imersão & $1,64 \mathrm{a}$ & $1,36 \mathrm{a}$ & $1,18 \mathrm{a}$ \\
\hline Média & 1,52 & 1,31 & 1,24 \\
\hline C.V. $(\%)$ & 17,3 & 16,6 & 10,7 \\
\hline
\end{tabular}

Valores seguidos da mesma letra, na coluna, não diferem entre si, pelo teste de Tukey, a 5\% de probabilidade. 
restritos, contrastando com o seu efeito consistente sobre a coloração da casca do fruto. Em geral, esta divergência pode ser atribuída ao fato de que o etefon penetra muito superficialmente (poucos milímetros) na cutícula ou casca do fruto, em grande parte não atingindo a sua polpa, além de não promover a produção endógena de etileno no abacaxi, conforme observado por Soler (1992) em frutos da cv. Smooth Cayenne.

Os resultados aqui obtidos para a cultivar Pérola, em grande parte, corroboram os relatados por outros autores sobre frutos de abacaxi cv. Smooth Cayenne. Poucos foram os efeitos significativos do etefon sobre os atributos da polpa, e estes foram positivos para a sua aplicação sob a forma de imersão rápida em relação à aplicação pré-colheita, prática comum para frutos da cv. Smooth Cayenne. O tratamento por imersão pós-colheita evita qualquer risco de o etefon atingir e causar a indução floral precoce das mudas do tipo filhote. Neste trabalho, a aplicação précolheita do etefon, sob a forma de jato em filete dirigido a um lado do fruto, não comprometeu este material de plantio, não se constatando incidência de floração durante a ceva e os primeiros 12 meses do ciclo após o plantio no campo.

\section{CONCLUSÕES}

1. A utilização do etefon acelera o amarelecimento de frutos do abacaxi cv. Pérola, sem afetar a firmeza da casca nem os principais atributos (firmeza, coloração, translucidez, teores de sólidos solúveis totais e de acidez total e a relação entre esses teores) da polpa.

2. A imersão rápida dos frutos, realizada logo após a colheita, é a melhor forma de aplicação de etefon, proporcionando maior uniformidade e rapidez na mudança de coloração da casca do fruto de abacaxi cv. Pérola, com efeitos favoráveis sobre a firmeza da casca, bem como a translucidez, o teor de sólidos solúveis totais (SST) e a relação SST/acidez da polpa.

3. Para se obter coloração amarela em $40 \%$ a $50 \%$ da casca, dentro do período suficiente para o seu transporte, sem refrigeração, aos mercados nacionais distantes (três a quatro dias), recomenda-se o tratamento de frutos de abacaxi 'Pérola' por imersão rápida, logo após a colheita, em calda aquosa de etefon nas concentrações de 500 a 2.000 $\mathrm{mg} \mathrm{L}^{-1}$, usando-se as mais altas para exigências maiores em relação à cor da casca.

\section{REFERÊNCIAS BIBLIOGRÁFICAS}

ABDULLAH, H.; ROHAYA, M.A.; SELAMAT, M.M. Handling and transportation trial of pineapple by sea shipment from Malaysia to the United Kingdom. Acta Horticulturae, Wageningen, v. 529, pp. 317-327, 2000.

ABELES, F.B.; MORGAN, P.W.; SALTVEIT, M.E. Ethylene in plant biology. San Diego: Academic Press, 1992.414p.
ABREU, C.M.P. de; CARVALHO, V.D. de; GONÇALVES, N.B. Cuidados pós-colheita e qualidade do abacaxi para exportação. Informe Agropecuário, Belo Horizonte, v.19, n.195, p.70-72, 1998.

ALVES, A. de A.; MATOS, A.P. de; REINHARDT, D.H.; CUNHA, G.A.P. da; SILVEIRA, J.R.; ALCÂNTARA, J. dos P.; CABRAL, J.R.S.; SOUZA, L.F. da S.; SILVA, N.M. da; SANCHES, N.F.; ALMEIDA, O.A. de; ANDRADE, R.L.L de. Recomendações técnicas para a cultura do abacaxi na região de Itaberaba, em condições de sequeiro. Salvador: EBDA, 1998. 8p. (Comunicado técnico, 19).

BOTREL, N.; ABREU, C. M. P. de. Colheita, cuidados e fisiologia póscolheita do abacaxi. Informe Agropecuário, Belo Horizonte, v.17, n.179, p.33-40, 1994.

BRASIL. MAPA. Secretaria de Apoio Rural e Cooperativismo. Divisão de Classificação de Produtos Vegetais. Instrução normativa/SARC $\mathbf{N}^{\mathbf{0}}$ 001, de $1^{\mathbf{0}}$ de fevereiro de 2002. Disponível em: <http// www.agricultura.gov.Br/dfpv/instruçãonormativa001.htm>. Acesso em: 06 fev. 2003.

BRASIL. MI. Abacaxi é bastante apreciado, mas difícil de escolher pela aparência. Frutifatos - Informação para a fruticultura irrigada. Brasília, DF, v. 2, n. 2, p. 26-27, 2002.

CUNHA, G.A.P. da; COELHO, Y. da; CALDAS, R.C. Qualidade do abacaxi tratado com os ácidos giberélico e 2-cloro-etil-fosfônico. Cruz das Almas: EMBRAPA-CNPMF, 1980. 3p. (Comunicado técnico, 2).

GIACOMELLI, E.J. Expansão da abacaxicultura no Brasil. Campinas: Fundação Cargill, 1982.79p.

GONÇALVES, N.B.; CARVALHO, V.D. Características da fruta. In: GONÇALVES, N.B. Abacaxi: pós-colheita. Brasília: Embrapa Comunicação para Transferência de Tecnologia, 2000. p.13-27. (Frutas do Brasil , 5).

POIGNANT, A. La maturation controlée de l'ananas. Fruits, Paris, v. 26, n.1, p. 23-35, 1971.

Programa Brasileiro para a modernização da horticultura. Normas de Classificação do Abacaxi. São Paulo: Centro de Qualidade em Horticultura (CQH), CEAGESP, 2003. (CQH. Documentos, 24)

REBOLLEDO M.A.; URIZA-ÁVILA, D.; REBOLLEDO, M.L. Tecnologia para la produccíon de piña em México. Vera Cruz: INIFAP-CIRGOC, 1998. 159p. (Folleto Técnico, n. 20)

REINHARDT, D.H. A floração natural do abacaxizeiro. Cruz das Almas: EMBRAPA, 1998. (EMBRAPA- CNPMF. Abacaxi em Foco, 10).

SEI (Superintendência de Estudo Econômico e Sociais da Bahia). Análise dos atributos climáticos do Estado da Bahia. Salvador, 1998. 85p. (Série Estudos e Pesquisa, 38).

SOLER, A. Métabolisme de l'ethephon dans l'epiderme de l'ananas (Ananas comosus, (L.) Merrill). Fruits, Paris, v. 47, n. 4, p. 471-477, 1992. 